\title{
Detection of Organo-Sulphur Volatiles in Allium sativum by Factorial Design
}

Raja Chekki ${ }^{1,2}$, Hanen Najjaa ${ }^{3^{*}}$, Nacim Zouari ${ }^{4}$, Ákos Máthé ${ }^{5}$ and Nabiha Bouzouita ${ }^{1,2}$

${ }^{1}$ Laboratoire de Chimie Organique et Structural, Faculté des Sciences de Tunis, Université de Tunis El Manar, Tunis, Tunisia

${ }^{2}$ Ecole Supérieure des Industries Alimentaires, Université de Tunis El Manar, Tunis, Tunisia

${ }^{3}$ Laboratoire d'Ecologie Pastorale, Institut des Régions Arides, Médenine, Tunisia

${ }^{4}$ Institut Supérieur de Biologie Appliquée de Médenine, Université de Gabès, Médenine, Tunisia

${ }^{5}$ Faculty of Agricultural and Food Sciences University of West Hungary, Mosonmagyaróvár, Hungary

\begin{abstract}
The influence of temperature and time of heating on the production and composition of organosulfur compounds (OSC) in Allium sativum were investigated in a two-level design with two factors. The organosulfur compounds were identified by Headspace-GC-MS. It was established that temperature plays an important role in the regulation of the production of monosulfides and trisulfides. The effect of both negative and positive temperatures on the production and decomposition of OSC were showed. Although, monosulfides and trisulfides were totally absent at the beginning of incubation, several mono- and trisulfides were detected in high proportions at $120^{\circ} \mathrm{C}$ during the 30 minutes incubation period. It appears that high temperature reduces the amount of disulfides, which are converted to monosulfides and trisulfides.
\end{abstract}

Keywords: Allium sativum; Organosulfur compounds; Factorial design; Headspace-GC-MS

\section{Introduction}

Allium species, especially garlic (Allium sativum) have been cultivated not only as spice but also as medicinal plants all over the world. Garlic (Allium sativum) is one of the earliest known medicinal plants. Its cloves had been used as a cure for many diseases in ancient Egypt and are mentioned in the Ebers Papyrus [1]. In this Codex of Ebers, 22 formulas of garlic were specified for the treatment of various disorders including heart problems, headache, bites, parasites and even tumors [2]. These considerations make the clinical exploitation of garlic derivatives/extracts an attractive and favorable strategy in therapeutic uses. As a result, many epidemiological studies have been conducted to scientifically validate the multi-beneficial effects of garlic on health [3]. The health beneficial effects of garlic and other Allium species have made the family Alliaceae an extremely promising research topic. Recently, studies were published on the potential medicinal uses of garlic by Pedraza-Chaverri et al. [4], Banerjee and Maulik [5] and Abdel-Daim et al. $[1,6]$. Special importance has been attributed to regular garlic consumption, especially in the prevention of cardiovascular diseases $[7,8]$. Moreover, cholesterol lowering, hypoglycemic, immunestimulatory, anti-microbial and even anti-cancer properties have been reported for garlic compounds [9-13]. Epidemiological studies clearly show the correlation between moderate garlic intake and a low cancer incidence with no health risk to consumers [14,15]. A case-control study has been performed on different geographical areas located in different countries (China [16]; Japan [17]; Italy [18]; Netherlands [19] and Venezuela [20]). This beneficial effect of garlic is attributed to their bioactive compounds such as diallyl sulphide (DAS) and other organosulfur compounds (OSC), which have the ability to prevent cancer by acting as efficient free radical scavengers [1].

Ninety-five percent of the sulfur compounds in intact garlic cloves have been found in two chemical classes in similar abundances: the $\gamma$-glutamyl-S-alkylcysteines and the S-alkylcysteine sulfoxides (alliin), which represent most abundant sulfur compound in garlic [21].

In fresh garlic alliin is present at $10 \mathrm{mg} / \mathrm{g}$, while in dried garlic its level is $30 \mathrm{mg} / \mathrm{g}$ [2]. When garlic cloves are cut, crushed, or chopped (even when the powder of dried cloves becomes wet in a non-acid solution), the odorless cysteine sulfoxides are rapidly converted into a new class of compounds, the thiosulfinates, which are responsible for the odor of freshly chopped garlic. In fact, the odourless compound alliin is converted to allicin, via allinase enzyme. Allicin is the main biologically active component of garlic clove extracts representing about $70 \%$ of all thiosulfinates formed in crushed garlic and gives the garlic its characteristic smell [1].

The composition of OSC can vary according to Allium species [22], plant cultivation or storage conditions and processing methods [23] Some OSC are absent in the bulbs and require mechanical exposure like cutting, crushing or chewing to be synthesized. According to Verma [24], whole garlic bulbs contain 16 OSC versus the 23 OSC of the crushed bulbs [24]. The cytoplasm of intact cloves contains biologically inactive $\gamma$-glutamylcysteine and S-alkylcysteine sulfoxides that serve as precursors for the volatile thiosulfinates $[25,26]$. Due to their high instability, the volatile thiosulfinates are degraded, within 24 hours, into both "second generation products" like oil-soluble mono-, di- and triallylsulfides (DAS, DADS, DATS) and vinyldithiins, thioacroleines, as well as ajoene [27-29]. These possess considerable biological activity and thus, possibly, represent the actual biologically active compounds [25]. Since garlic is more often consumed in a cooked, or dried, rather than raw state, the effects of these processing methods on its organosulfur compounds raise several questions and important concerns. As heat inactivates enzymes, it is generally accepted that heating garlic cloves inactivates alliinase and consequently prevents the formation of both allicin and other thiosufinates [29]. Several studies have been conducted to assess the active metabolites of garlic. Experimental data suggest that each activity is strongly dependent on the used methods [30] and the health benefits can also vary with preparation [31]. As a result, the different garlic formulations available at the market vary in their chemical composition.

In view of the differences in the organosulfur composition of different garlic preparation, the aim of the present study is to elucidate the analytical behaviour of OSC, by evaluating the impact of heating

*Corresponding author: Hanen Najjaa, Laboratoire d'Ecologie Pastorale, Institut des Régions Arides, Médenine, Tunisia, Tel: + 216 97454697; Fax: + 216633006 ; E-mail: hanen.najjaa@yahoo.fr

Received February 12, 2016; Accepted March 03, 2016; Published March 10, 2016

Citation: Chekki R, Najjaa H, Zouari N, Máthé Á, Bouzouita N (2016) Detection of Organo-Sulphur Volatiles in Allium sativum by Factorial Design. Nat Prod Chem Res 4: 211. doi:10.4172/2329-6836.1000211

Copyright: $\odot 2016$ Chekki R, et al. This is an open-access article distributed under the terms of the Creative Commons Attribution License, which permits unrestricted use, distribution, and reproduction in any medium, provided the original author and source are credited. 
temperature and time on the OSC composition of A. sativum. Mainly, the formation of mono-, di- and trisulfides was studied in order to reveal the variation of OSC, conducted by the variation of analytical parameters using an experimental design.

\section{Experimental}

\section{Plant material}

Plants of A. sativum cv. "Softneck" were randomly collected in October 2012 from a cultivated population, in Manouba-Tunisia.

\section{Experimental design}

The effect of heating temperature and heating time, as variables, on the production of OSC was evaluated in a $2^{2}$ factorial design (Table 1).

The behavior of the system was described using the following second-order polynomial:

$$
Y_{1}=a_{0}+a_{1} T+a_{2} t_{\text {min }}+a_{2} T x t_{\text {min }}
$$

Where, $\mathrm{Y}$ is the predicted response, $\mathrm{a}_{\mathrm{o}}$ is the interception coefficient, $\mathrm{a}_{1}$ are the linear terms, $\mathrm{a}_{12}$ are the interaction terms, and $\mathrm{T}$ and $\mathrm{t}_{\text {min }}$ are the coded levels of the independent variables temperature and time, respectively. The models of the two responses were expressed in terms of coded variables, without taking into account the statistically insignificant terms.

Table 1 represents the variables of interest and their real values at the levels set in the design. Temperature levels were $35^{\circ} \mathrm{C}$ and $120^{\circ} \mathrm{C}$; times were 3 and $30 \mathrm{~min}$. In the design matrix, the effects of two variables on formation of selected OSC were evaluated. The runs were randomized for statistical purposes. Then, the data from run 1 to run 4 were computed and plotted using Design Minitab 17 software. The most important Headspace-GC-MS variables were selected based on the literature and preliminary tests undertaken to assess the tendencies of the factors and which had the greatest influence on responses for selected OSC.

\section{Analytical procedure}

Two grams of garlic slices, previously homogenized, were weighed into $15 \mathrm{ml}$ screw-cap aroma headspace vials, which were closed with an aluminum seal. The vial was placed onto a magnetic stirrer. Headspace extraction was carried out immediately after sample preparation. Volatiles were extracted by exposing the solid-phase micro extraction (SPME) fiber to the headspace (HP 7694) of a sample vial. The compounds extracted were withdrawn through the septum by a gas syringe and analyzed by gas chromatography.

The GC-MS analysis was carried out on an Agilent 6890N Net Work GC System model equipped with a DB-5 column (JandW Scientific, USA) at dimensions of $50 \mathrm{~m} ; 0.32 \mathrm{~mm}$ ID and $0.25 \mathrm{~mm}$ film thickness. Average helium carrier gas flow rate: $1 \mathrm{ml} /$ minutes, column split ratio: 50:1, injector and detector temperatures: $200^{\circ} \mathrm{C}$ and $230^{\circ} \mathrm{C}$, respectively. The column oven temperature was held at $60^{\circ} \mathrm{C}$ for 1.5 minutes, then programmed to $100^{\circ} \mathrm{C}$ at $2^{\circ} \mathrm{C} / \mathrm{min}$ and then to $150^{\circ} \mathrm{C}$ at $10^{\circ} \mathrm{C} / \mathrm{min}$. The injected volume was $1 \mathrm{ml}$. The ionization energy was at $70 \mathrm{eV}$ with a scan time of $1 \mathrm{~s}$ and a mass range of 40-300 amu. The components of the garlic preparation were identified by comparing their mass spectra with those of a computer library (Wiley $27 \mathrm{~L}$ ). The relative percentages of components were obtained by peak-area normalization without correction factors.

\section{Results and Discussion}

Temperature and time incubation were evaluated and optimized by means of a factorial design and the obtained results were evaluated by an analysis of variance (ANOVA).

\section{Analysis of the mode 1}

Table 2 shows the main volatile compounds of garlic obtained after different treatments. The most common allyl sulfides were diallyl disulfide (DADS), diallyl sulfide (DAS), diallyl trisulfides (DATS) and methyl allyl trisulfides (MATS) as found previously by Kalra et al. [13]. The pharmacological activity of garlic has been attributed to the presence of organosulfur compounds, mostly related to oil-soluble allyl sulfides such as DATS, DADS and DAS. Allyl sulfides showed valuable action in the liver, which could be used for protection of normal liver cells or for improvement of liver damage. Numerous researches have approved the antioxidant activity of DAS as it suppressed cytotoxicity and oxidative tissue damage by increasing antioxidant enzyme activities and decreasing lipid peroxidation. Therefore, it can be used as a dietary preventive agent [6]. The results of GC-MS analysis of the garlic constituents showed that heating increased the proportions of some volatile compounds in garlic, such as DAS (from 0 to $14.70 \%$ ), methyl allyl trisulfide (from 0 to $14 \%$ ) and diallyl trisulfide (from 0 to $18.30 \%$ ). The methyl allyl disulfide and diallyl disulfide contents increased after the heat treatment at $120^{\circ} \mathrm{C}$ by $14 \%$ and $86 \%$, respectively. The effect of heat treatment at $35^{\circ} \mathrm{C}$ was less explicit with an increase of $5 \%$ and $42.40 \%$, respectively. It was observed that dimethyl sulfide (DMS), constituents completely vanished at $35^{\circ} \mathrm{C}$ for $3 \mathrm{~min}$ and at $120^{\circ} \mathrm{C}$ for $30 \mathrm{~min}$. However, Matan et al. [32] showed that heat curing at $100^{\circ} \mathrm{C}$ increased the proportion of diallyl disulfide from 38.86 to 53.29 , while it slightly reduced proportions of other constituents, such as diallyl sulfide (from 19.81 to 15.22) as compared to the effect of $30^{\circ} \mathrm{C}$ treatments. It can be concluded that heat (at high temperatures) enhanced the formation of diallyl sulfide and simultaneously slightly induced the decomposition of diallyl disulfide. Transformation also seems to lead to the formation of polysulfide's that are present in multiple garlic preparations in substantial quantities and are comparatively stable [13]. DAS is an active organic sulphur compound derived from garlic that can suppress cytotoxicity induced by chemicals in animal models and is well-known for its antioxidant properties. DAS and related compounds have been shown to suppress oxidative tissue damage by increasing antioxidant enzymes activities and decreasing malondialdehyde level in lung and kidney tissues [6].

Sulfur compounds are also present in garlic oil. They can be classified into two main groups according to their cyclic (contains the two vinyldithiin isomers, e.g., 2-vinyl-1,3-dithiane) or acyclic (consists of various mono- to polysulfide's, e.g., diallyl disulfide and diallyl sulfide) structures [33]. Detection of diallyl disulfide and diallyl trisulfides after heating at high temperature was in accordance with the finding of Kimbari [33] and Abu-Lafi et al. [34], who showed that formation of various acyclic compounds from garlic could be promoted by heat. A high level of acyclic compounds was observed in an extraction procedure at high temperatures, while extraction at room temperature greatly reduced and increased levels of acyclic and cyclic compounds,

\begin{tabular}{|c|c|c|c|}
\hline Experiment & Run & $\mathbf{T}^{\mathbf{a}}$ & $\mathbf{t}^{\mathbf{b}}$ \\
\hline 1 & 3 & 30 & 3 \\
\hline 2 & 2 & 120 & 35 \\
\hline 3 & 1 & 30 & 35 \\
\hline 4 & 4 & 120 & 3 \\
\hline
\end{tabular}

aThe variable $\mathrm{T}\left({ }^{\circ} \mathrm{C}\right)$ represent the vial incubation temperature.

${ }^{b}$ The variable $t(\mathrm{~min})$ represent the vial incubation time.

Table 1: Independent variables and design layout in the $2^{2}$ factorial design. 


\begin{tabular}{|c|c|c|c|c|c|}
\hline \multicolumn{2}{|c|}{ Organo-Sulfur Compounds } & \multicolumn{4}{|c|}{ Relative content $(\%)$ at } \\
\hline & & $\left(35^{\circ} \mathrm{C}, 3 \mathrm{~min}\right)$ & $\left(35^{\circ} \mathrm{C}, 30 \mathrm{~min}\right)$ & $\left(120^{\circ} \mathrm{C}, 3 \mathrm{~min}\right)$ & $\left(120^{\circ} \mathrm{C}, 30 \mathrm{~min}\right)$ \\
\hline & Methyl allyl sulfide (MAS) & 0 & 0.52 & 2.50 & 5.70 \\
\hline & Dimethyl sulfide (DMS) & 0 & 0.80 & 0.80 & 0 \\
\hline & Diallyl sulfide (DAS) & 0 & 0 & 3.20 & 14.70 \\
\hline $\mathrm{H}_{2}$ & Methyl allyl disulfide (MADS) & 14 & 22.70 & 12.9 & 5 \\
\hline H & Diallyl disulfide (DADS) & 86 & 76 & 69.10 & 42.40 \\
\hline & Methyl allyl trisulfide (MATS) & 0 & 0 & 5 & 14 \\
\hline & Diallyl trisulfide (DATS) & 0 & 0 & 6.60 & 18.30 \\
\hline & Total monosulfides & 0 & 0.52 & 5.7 & 20.4 \\
\hline & Total disulfides & 100 & 99.5 & 82.8 & 47.4 \\
\hline & Total trisulfides & 0 & 0 & 11.6 & 32.3 \\
\hline
\end{tabular}

Table 2: Effect of heating temperature and heating time on main OSC of garlic (A. sativum).

respectively [33]. Acyclic compounds, such as diallyl disulfide, are formed by thermal degradation of thiosulfinates previously produced by garlic's unstable main precursor, allicine (Figure 1) [35]. According to these authors, diallyl disulfide can oxidize back to allicin and this might explain a reduction in the proportion of diallyl disulfide after 30 min of incubation at $120^{\circ} \mathrm{C}$ temperature.

In view of the fact that garlic is normally consumed in cooked foods and as dried spice, it has been also investigated by several authors that heating might affect the chemical composition of garlic including its antioxidant properties. It has been also established that heating of garlic cloves for $60 \mathrm{~s}$ using microwaves reduces its anticancer properties [36] and the heating of garlic extracts for $10 \mathrm{~min}$ at $100^{\circ} \mathrm{C}$ reduces the ability to inhibit platelet aggregation [37]. In contrast, the $\mathrm{OH}^{*}$ scavenging properties of garlic were essentially preserved when garlic extracts were heated [38]. Shobana and Naidu [39] found that the lipid peroxidation inhibiting capacity of garlic was not affected by boiling (30 min at $100^{\circ} \mathrm{C}$ ). Recently, it was also found that the ability of garlic extracts to inhibit $\mathrm{Cu}^{2+}$ induced lipoprotein oxidation in human serums was not affected by the heating whole garlic cloves or extracts of garlic powder [38]. By contrast, Yin and Cheng [40] found that heating treatment $\left(100^{\circ} \mathrm{C}\right.$ for $15 \mathrm{~min}$ in an oven) of chopped garlic reduced the ability to inhibit lipid peroxidation. Furthermore, the hydrogen peroxide radical scavenging ability of garlic decreased in the heat treated extract of garlic powder [38]. These findings indicates that the effect of heating on biological activities of garlic depend on the allinase activity and the consequent formation of thiosulfinates [22].

\section{Main and interaction effects: Half-normal probability plot and diagram of Pareto}

Quantitatively, the estimated effects of temperature and time gave main effect or interaction effect via least squares estimation (Figure 2). Based on these estimates we could construct a list of the main effects and interactions, according to the order of the effect magnitude. All the effects that lie along the line were negligible, whereas larger ones are far from the line. It could be established, the main effects including the heating temperature (A) effect, influenced the monosulfides and the trisulfides formation within the levels and conditions tested. The fit of the models was also checked by the diagram of Pareto. It could be confirmed that the predicted response values are in good agreement with the experimental data and that temperature exhibit the more important effects on production of trisulfides mainly. Higher polysulfides are formed at higher temperatures [26].

In accordance with this study, the following ranking can be established: monosulfides $A>B>A B$, disulfides $A>A B>B$ and trisulfides $\mathrm{A}>\mathrm{AB}>\mathrm{B}$, where $\mathrm{A}$ is the incubation temperature and $\mathrm{B}$ the incubation time (Figures 2 and 3 ).

\section{ANOVA analysis}

In order to ensure a good model, test for significance of the regression model and test for significance on individual model coefficients must be performed. An ANOVA table is commonly used to summarize the tests that were performed and to evaluate the statistical significance of the model. Table 3 shows the correlation, $F$-value and $P$-value of the main mono-, di- and trisulfides compounds as a response. The statistical significance of the models (time and temperature needed for the production of more OSC) was determined by an $F$-value and $P$-value. Corresponding $P$-values suggest that, among the test variables used in this study, a (temperature) is significant since $P$-values were less than 0.05 for the monosulfides and trisulfides. The fit of the models was checked by $\mathrm{R}^{2}$, which was found to be 0.995 and 0.998 for the

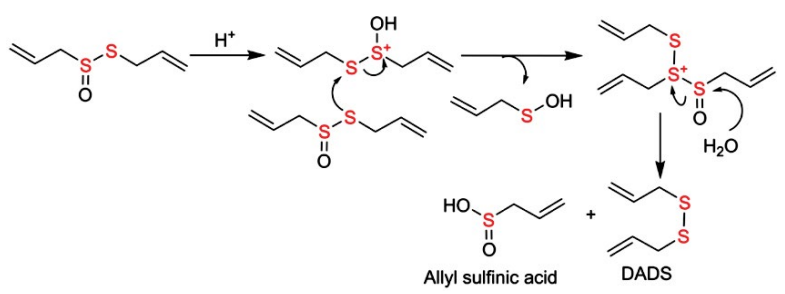

Figure 1: Proposed mechanism of chemical transformation from thiosulfinates to organosulfides through elimination and acid-mediated nucleophilic substitution reactions [37]. 

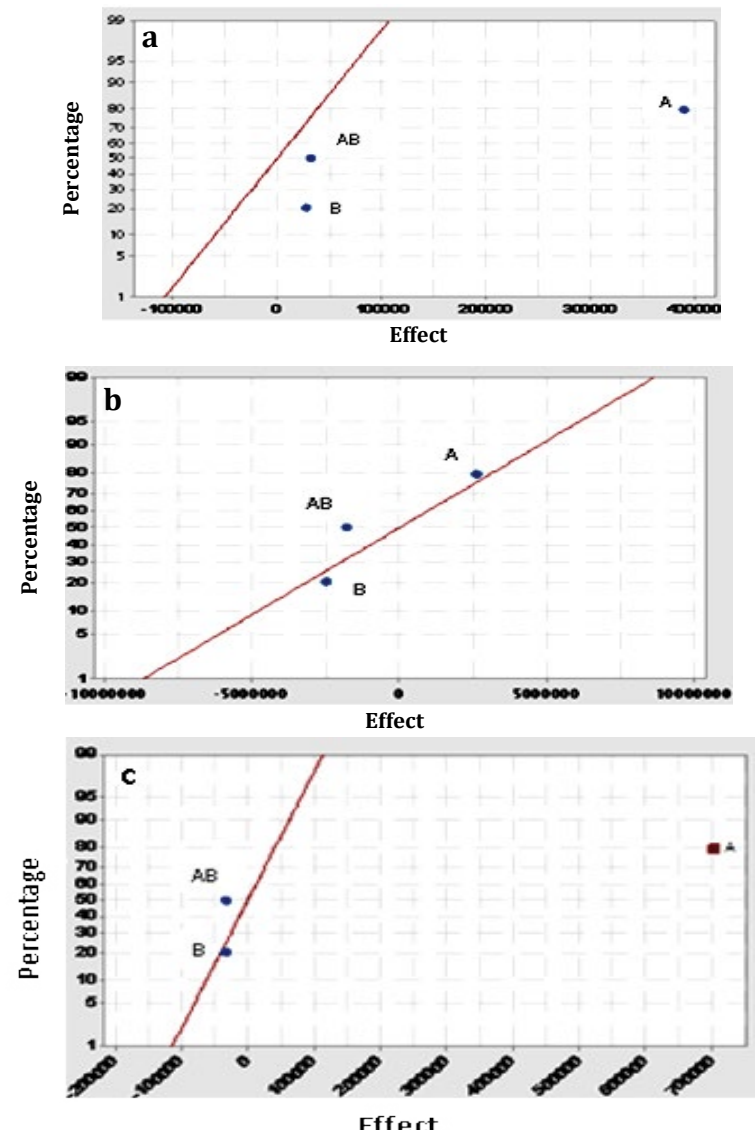

Figure 2: Half-normal probability plot (Henry plot) for produced mono- (a) di(b) and trisulfides (c) by garlic preparation at different temperature and time of heating. Factors $A$ and $B$ represent the $T\left({ }^{\circ} \mathrm{C}\right)$ and the $t(\min )$, respectively. ( $\square$ ): significant $(p<0.05)$ and $(\bullet)$ : not significant.

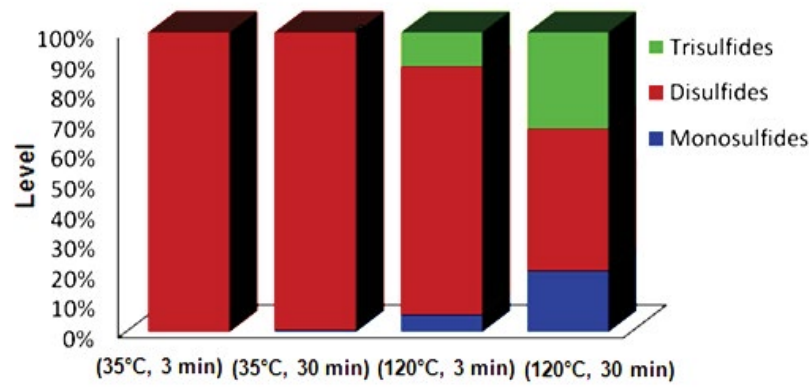

Figure 3: Decomposition of disulfides to mono- and trisulfides after heating at $120^{\circ} \mathrm{C}$ and incubation time of 3 and $30 \mathrm{~min}$.

produced trisulfides and the monosulfides, respectively. In fact, these values which were close to 1 were acceptable and indicated that there was an adequate goodness-of-fit. A small value of $\mathrm{R}^{2}$ indicated a poor relevance of the dependent variables in the model [41]. The $P$-value is used as a tool to check the significance of each coefficient, which also indicated the interaction strength between each independent variable.

The evaluation of the obtained results by analysis of variance (ANOVA) (Table 3) showed that temperature has a direct statistically significant effect on the monosulfides and trisulfides formation $(P<0.05)$. The time was non-significant for sulfides formation or decomposition $(P>0.05)$. Heat appeared to have positively affected the production of organosulfur compound by garlic and this temperature dependence was more pronounced for monosulfides and trisulfides. In fact, increased time and increased temperature showed negative main effects on disulfides concentration but a significant $(P<0.05)$ positive effect on mono- and trisulfides formation. According to Figure 3 , heating temperature $\left(120^{\circ} \mathrm{C}\right)$ appeared to strongly enhance the production of monosulfides and increasing from 0 to $20.4 \%$ and from 0 to $32.3 \%$ for trisulfides. In contract to the situation with monosulfides and trisulfides, heating temperature affect the decomposition of disulfides. These result was confirmed by the corresponding correlation values given on Table 4 , suggesting that composition of monosulfides and trisulfides was much correlated $\left(P<0.05\right.$ and $\left.\mathrm{R}^{2}=0.98\right)$.

From a combination of the process variables estimated and the ANOVA results, a polynomial model with statistical significance can be generated. This model, quantitatively elucidating the effects of process variables with statistical significance, is presented as follows: In order to maximize mono, di and trisulfides, which were considered as target responses, values of linear model $2^{2}$ calculated by ANOVA are given below:

$$
\begin{aligned}
& \text { Monosulfides }=-146616+4175 \mathrm{~T}-715.5 \mathrm{t}_{\text {min }}+24.96 \mathrm{~T} \times \mathrm{t}_{\text {min }} \\
& \text { Disulfide }=-2316248+67099 \mathrm{~T}+102315 \mathrm{t}_{\text {min }}-2172 \mathrm{~T} \times \mathrm{t}_{\text {min }} \\
& \text { Trisulfides }=-306309+8752 \mathrm{~T}+993.2 \mathrm{t}_{\text {min }}-28.38 \mathrm{~T} \times \mathrm{t}_{\text {min }}
\end{aligned}
$$

\section{Conclusions}

Given the complexity of the chemical composition of garlic, our proposed new analytical procedure can be a useful alternative to predict the presence of OSC in garlic, with regards to the preparation conditions (specifically temperature and time) and method. Effects of temperature and time as operational parameters were investigated on the organosulfur production of garlic. In the present work, we demonstrate that the OSC composition of A. sativum is due not only to edaphoclimatic conditions but also to the chromatographic parameters. The $2^{2}$ factorial design experiment used in this study was found to be very effective in the evaluation of OSC formation or decomposition, as a function of time and temperature. Increased temperature indicated negative main effects on disulfides concentration, and by a contrast, a positive effect on mono and trisulfides formation. We can deduce that disulfides are thermally labile compounds and mono- and polysulfides are their breakdown products.

\section{References}

1. Abdel-Daim MM, Abdelkhalek NK, Hassan AM (2015) Antagonistic activity of

\begin{tabular}{|c|c|c|c|c|}
\hline $\begin{array}{c}\text { Organo-Sulfur } \\
\text { Compounds }\end{array}$ & $\mathbf{R}^{2}$ model & & $\boldsymbol{F}$-Value & $\boldsymbol{P}$-value \\
\hline Monosulfides & 0.995 & $\mathrm{~T}\left({ }^{\circ} \mathrm{C}\right)$ & 185.33 & 0.047 \\
\cline { 3 - 5 } & & $\mathrm{t}(\mathrm{min})$ & 1.32 & 0.456 \\
\hline \multirow{2}{*}{ Disulfides } & 0.623 & $\mathrm{~T}\left({ }^{\circ} \mathrm{C}\right)$ & 1.14 & 0.48 \\
\cline { 3 - 5 } & & $\mathrm{t}(\mathrm{min})$ & 0.51 & 0.605 \\
\hline \multirow{2}{*}{ Trisulfides } & 0.998 & $\mathrm{~T}\left({ }^{\circ} \mathrm{C}\right)$ & 467.5 & 0.029 \\
\cline { 3 - 5 } & & $\mathrm{t}(\mathrm{min})$ & 1 & 0.5 \\
\hline
\end{tabular}

Table 3: ANOVA results for time period and temperature needed for the production of organo-sulfur compounds.

\begin{tabular}{|c|c|c|}
\hline Correlation between & $\mathbf{R}^{\mathbf{2}}$ & $\boldsymbol{P}$-value \\
\hline Mono- and disulfides & 0.569 & 0.431 \\
\hline Di- and trisulfides & 0.702 & 0.298 \\
\hline Mono- and trisulfides & 0.984 & 0.016 \\
\hline
\end{tabular}

Table 4: Correlation between organo-sulfur compounds. 
dietary allicin against deltamethrin-induced oxidative damage in freshwater Nile tilapia; Oreochromis niloticus. Ecotoxicol Environ Saf 111: 146-152.

2. Block $E$ (1985) The chemistry of garlic and onions. Sci Am 252: 114-119.

3. Scherer C, Jacob C, Dicato M, Diederich M (2010) Allylsulfides as Bioactive Compounds with Chemotherapeutic and/or Chemopreventive Effects. Comp Bio Nat Pro 3: 1-33.

4. Pedraza-Chaverrí J, Tapia E, Medina-Campos O N, Ángeles Granados M, Franco M, et al. (1998) Garlic prevents hypertension induced by chronic inhibition of nitric oxide synthesis. Life Sci 62: PL71-PL77.

5. Banerjee SK, Maulik SK (2002) Effect of garlic on cardiovascular disorders: a review. Nutr J 1: 4

6. Abdel-Daim MM, Abdou RH (2015) Protective Effects of Diallyl Sulfide and Curcumin Separately against Thallium-Induced Toxicity in Rats. Cell J 17: 379388.

7. Galeone C, Pelucchi C, Dal Maso L, Negri E, Montella M, et al. (2009) Allium vegetables intake and endometrial cancer risk. Public Health Nutr 12: 1576-

8. Rahman K, Lowe GM (2006) Garlic and cardiovascular disease: a critical review. J Nutr 136: 736S-740S.

9. Amagase $\mathrm{H}$, Petesch BL, Matsuura H, Kasuga S, Itakura $\mathrm{Y}$ (2001) Intake of garlic and its bioactive components. J Nutr 131: 955S-62S.

10. Balkwill F, Mantovani A (2001) Inflammation and cancer: back to Virchow? Lancet 357: 539-545.

11. Borrelli F, Capasso R, Izzo AA (2007) Garlic (Allium sativum L.): adverse effects and drug interactions in humans. Mol Nutr Food Res 51: 1386-1397.

12. Goncagul G, Ayaz E (2010) Antimicrobial effect of garlic (Allium sativum). Recent Pat Antiinfect Drug Discov 5: 91-93.

13. Kalra N, Arora A, Shukla Y (2006) Involvement of multiple signaling pathways in diallyl sulfide mediated apoptosis in mouse skin tumors. Asian Pac J Cancer Prev 7: 556-562.

14. Kim JK, Kwon O (2009) Garlic intake and cancer risk: an analysis using the Food and Drug Administration's evidence-based review system for the scientific evaluation of health claims. Am J Clin Nutri 89: 257-264.

15. Salem S, Salahi M, Mohseni M, Ahmadi H, Mehrsai A, et al. (2011) Major dietary factors and prostate cancer risk: a prospective multicenter case-control study. Nutr Cancer 63: 21-27.

16. Takezaki T, Gao CM, Ding JH, Liu TK, Li MS, et al. (1999) Comparative study of lifestyles of residents in high and low risk areas for gastric cancer in Jiangsu Province, China; with special reference to allium vegetables. J Epidemiol 9 297-305.

17. Gao CM, Takezaki T, Ding JH, Li MS, Tajima K (1999) Protective effect of allium vegetables against both esophageal and stomach cancer: a simultaneous case-referent study of a high-epidemic area in Jiangsu Province, China. Jpn J Cancer Res 90: 614-621.

18. Pelucchi C, Bosetti C, Rossi M, Negri E, La Vecchia C (2009) Selected aspects of Mediterranean diet and cancer risk. Nutr Cancer 61: 756-766.

19. Dorant E, van den Brandt PA, Goldbohm RA (1996) A prospective cohort study on the relationship between onion and leek consumption, garlic supplement use and the risk of colorectal carcinoma in The Netherlands. Carcinogenesis 17: 477-484

20. Muñoz N, Plummer M, Vivas J, Moreno V, De Sanjosé S, et al. (2001) A casecontrol study of gastric cancer in Venezuela. Int J Cancer 93: 417-423.

21. Powolny AA, Singh SV (2008) Multitargeted prevention and therapy of cancer by diallyl trisulfide and related Allium vegetable-derived organosulfur compounds. Cancer Lett 269: 305-314.

22. Lawson LD (1998) Garlic: A Review of Its Medicinal Effects and Indicated Active Compounds. Phytomed Eur 14: 176-209.

23. Nencini C, Cavallo F, Capasso A, Franchi GG, Giorgio G, et al. (2007) Evaluation of antioxidative properties of Allium species growing wild in Italy. Phytother Res 21: 874-878.

24. Verma SK, Jain V, Verma D (2008) Garlic - "The spice of life": composition, cooking chemistry and preparations. J Herb Med Toxicol 2: 21-28.
25. Kamel A Saleh M (2000) Recent studies on the chemistry and biologica activities of the organosulfur compounds of garlic (Allium sativum). Stud Nat Prod Chem 23: 455-485

26. Lanzotti V (2006) The analysis of onion and garlic. J Chromatogr A 1112: 3-22

27. Amagase $\mathrm{H}$ (2006) Clarifying the real bioactive constituents of garlic. J Nutr 136: 716S-725S.

28. Münchberg U, Anwar A, Mecklenburg S, Jacob C (2007) Polysulfides as biologically active ingredients of garlic. Org Biomol Chem 5: 1505-1518.

29. Staba EJ, Lash L, Staba JE (2001) A commentary on the effects of garlic extraction and formulation on product composition. J Nutr 131: 1118S-9S.

30. Avato P, Tursil E, Vitali C, Miccolis V, Candido V (2000) Allylsulfide constituents of garlic volatile oil as antimicrobial agents. Phytomedicine 7: 239-243.

31. Jessica GC, Williams JD, Cross M, Chambers CC (2011) Analysis of Garlic Cultivars Using Head Space Solid Phase Microextraction/Gas Chromatography/ Mass Spectroscopy. Open Food Sci J 6: 1-4

32. Matan N, Ketsa S (2012) Effect of heat curing on antifungal activities of anise oil and garlic oil against Aspergillus niger on rubberwood. Int Biodeterior Biodegradation 75: 150-157.

33. Kimbaris AC (2006) Quantitative analysis of garlic (Allium sativum) oil unsaturated acyclic components using FT-Raman spectroscopy. Food Chem 94: 287-295.

34. Abu-Lafi S, Dembicki JW, Goldshlag P, Hanus LO, Dembitsky VM, et al (2004) The Use of the 'Cryogenic' GC/MS and on-Column Injection for Study of Organosulfur Compounds of the Allium sativum. J Food Comp Anal 17: 235245

35. Tocmo R, Liang D, Lin Y, Huang D (2015) Chemical and biochemical mechanisms underlying the cardioprotective roles of dietary organopolysulfides. Front Nutr 2: 1

36. Song K, Milner JA (1999) Heating garlic inhibits its ability to suppress 7 12-dimethylbenz(a)anthracene-induced DNA adduct formation in rat mammary tissue. J Nutr 129: 657-661.

37. Ali M, Bordia T, Mustafa T (1999) Effect of raw versus boiled aqueous extract of garlic and onion on platelet aggregation. Prostaglandins Leukot Essent Fatty Acids 60: 43-47.

38. Pedraza-Chaverrí J, Tapia E, Medina-Campos ON, Ávila-Lombardo R, ZúñigaBustos AB, et al. (2006) Reactive oxygen species scavenging capacity of different cooked garlic preparations. Life Sci 78: 761-770.

39. Shobana S, Naidu KA (2000) Antioxidant activity of selected Indian spices. Prostaglandins Leukot Essent Fatty Acids 62: 107-110.

40. Yin MC, Cheng WS (1998) Antioxidant Activity of Several Allium Members. J Agric Food Chem 46: 4097-4101.

41. Wen L (2011) Ultrasound-assisted extraction and structural identification of polysaccharides from Isodon lophanthoides var. gerardianus (Bentham) $\mathrm{H}$ Hara. Carbohydr Polym 85: 541-547. 